\title{
Cancer and Non-Cancer Risk of Arsenic in Drinking Water: A Case
} Study

\author{
Yadollah Ghafuri, ${ }^{1,2}$ Hossein Kamani, ${ }^{3}$ Edris Bazrafshan, ${ }^{4}$ Zahra Atafar, ${ }^{5}$ Mohammad Khazaie, ${ }^{2}$ and \\ Amir Hossein Mahvis ${ }^{5,6, *}$
}

\footnotetext{
${ }^{1}$ Department of Environmental Health Engineering, School of Public Health, International Campus, Tehran University of Medical Sciences, (IC-TUMS) Tehran, Iran

${ }^{2}$ Environmental Research Center, Qom University of Medical Science, Qom, Iran

${ }^{3}$ Health Promotion Research Center, Zahedan University of Medical Sciences, Zahedan, Iran

${ }^{4}$ Health Sciences Research Center, Torbat Heydariyeh University of Medical Sciences, Torbat Heydariyeh, Iran

${ }^{5}$ Department of Environmental Health Engineering, School of Public Health , Tehran University of Medical Sciences, Tehran, Iran

${ }^{6}$ Centers for Solid Waste Research, Institute for Environmental Research, Tehran University of Medical Sciences, Tehran, Iran

"Corresponding author: Amir Hossein Mahvi, Centers for Solid Waste Research, Institute for Environmental Research, Tehran University of Medical Sciences, Tehran, IR Iran. E-mail: amirhosseinmahvi@yahoo.com
}

Received 2017 May 11; Accepted 2017 September 11.

\begin{abstract}
Arsenic is a toxic element, which is found naturally in water sources. Due to its high toxicity it has become a serious problem in drinking water sources and also affects the health of communities. Therefore, in the present study, risk estimation and the probability of adverse health effects of exposure to arsenic from drinking water was evaluated in the rural areas of Qom province. Water samples were taken from 44 rural areas with regard to the number of rural areas and also the type of water distribution systems. The intensity, duration and frequency of exposure to arsenic in drinking water were determined. Then the hazard quotient and cancer risks ware calculated. Results showed that more than $16 \%$ of the rural population was exposed to arsenic with level above $10 \mu \mathrm{g} / \mathrm{L}$ in the rural regions of Kahak County $(10 \pm 6.29 \mu \mathrm{g} / \mathrm{L})$. Results of risk assessment showed that hazard quotient (HQ) were 1.7 and 2 , while the cancer risk (CR) were $76 \times 10^{-5}$ and $42 \times 10^{-4}$ for 2 groups of age 1 and 2 , respectively. The results indicated that the hazard quotient is higher than $1(\mathrm{HQ}>1)$ for group 1 and group 2 . For carcinogenic effects, the study indicated that the population in the Kahak region are exposed to arsenic in drinking water with the concentration of $>10 \mu \mathrm{g} / \mathrm{L}$ and they are at a very high risk for cancer, due to the fact that the cancer risk for the 2 groups are more than 7.6 and 42 times the environmental protection agency (EPA) criteria, respectively. Therefore it is recommended that at first, the source and water supply system in Kahak region is to be substituted with safe drinking water and to provide health facilities and screening tests for exposed populations.
\end{abstract}

Keywords: Risk Cancer, Arsenic, Drinking Water, Risk Assessment

\section{Introduction}

It is estimated that 200 million people throughout the world are exposed to arsenic in drinking water that exceed the recommended limit of $10 \mu \mathrm{g} / \mathrm{L}$ as set out in the guidelines of the world health organization (WHO) (1). Arsenic (As) is a toxic element, which is found naturally in water sources, soil, and sediments $(1,2)$. The nature of the soil parent material appears to be the main factor determining the As concentration in soils, although due to its low supergene mobility, the soils are slightly enriched in As compared with their soil parent rocks $(3,4)$. The consumption of arsenic from contaminated water may adversely affect human health. The international agency for research on cancer (IARC) classifies (As) as a group 1 based on epidemiological studies (5). The exposure of arsenic from drinking water has been reported in many countries such as: Tai- wan, Argentina, Chile, Mexico, India, Bangladesh, China, Vietnam, and Cambodia. The most common sign of exposure to arsenic is hyper pigmentation, especially on the trunk, and keratosis on the palms and soles. These skin lesions generally develop within 5 - 10 years after the initial exposure, although shorter latencies have been reported. Many other signs and symptoms have also been noted such as chronic cough, crepitation's in the lungs, diabetes mellitus, hypertension, and weakness $(1,6)$.

The WHO guideline and permissible limit by health ministry of Iran for Arsenic in drinking water is $10 \mu \mathrm{g} / \mathrm{L}$ (6). Qom province is one of the central regions in Iran with a harmful as well as dry climate and with many economic and cultural potentialities. The rural population of Qom province is about 84000 inhabitants, where water supply systems have considerable challenges regarding water quality and quantity. High concentration of As and 
the physico-chemical parameters in groundwater in rural drinking water in Qom province has been previously reported. Mining activity and geology of the study area including rural county of Qom province and possible leaching of As in ground water has an important factor in the health of inhabitants $(1,2)$. The present study addresses these through a human health risk assessment in the rural of Qom province for exposure by arsenic in drinking water.

\section{Methods}

\subsection{Description of Study}

Methodology of the study was anticipated in 2 phases including: environmental monitoring of arsenic in rural water supply and the arsenic health risk assessment in rural regions having concentration of arsenic higher than Iranian national drinking water standard (>10 $\mu \mathrm{g} / \mathrm{L})$. The limitation of the Qom rural with consideration to the Qom province contains 5 counties and 180 rural regions that are presented in Figure 1.

\subsection{Sampling Analysis}

Water samples were taken from 44 rural areas of the Qom province with regard to the number of rural areas and also the type of water distribution systems. Factors such as the kind of water sources were considered. The sampling period was from May through October 2016. The information including sample code, name of sampler, the geographical location of sampling, and sampling date were recorded for each sample. Physical parameters such as: alkalinity, electrical conductivity, temperature, and $\mathrm{pH}$ were measured (7-9).

An automatic absorption spectrometer (AAS) equipped with graphite furnace was applied for sample measurements. Hydrochloric acid $(0.02 \mathrm{~N})$ was applied to preserve the samples prior to delivery to the laboratory. The analytical LOD, calculated as 3 times the standard deviation (SD) of the lowest detectable calibration standard $(0.2 \mu \mathrm{g} / \mathrm{L})$, was determined. The total alkalinity and total hardness of the samples is being determined by standard titrimetric methods (7-9).

\subsection{Human Health Risk Assessment}

Considering the process of human health risk assessment, 4 steps were taken including hazard identification, dose-response assessment, exposure assessment, and risk characterization (9). In the risk assessment, addressing uncertainties is necessary in order to avoid inaccurate or biased estimates. Therefore Monte Carlo simulation and sensitivity analysis were implemented using the @risk software (version 6.0, Palsida Corporation, USA) (10).

\subsubsection{Hazard Identification}

In this study, hazard identification related to the concentration of arsenic that must be concern and adverse effects were determined.

\subsubsection{Dose- Response Assessment}

Dose-response assessment for ingested toxicants in terms of reference dose (RfD) for non-cancer effects and cancer slope factor (CSF) for cancer effects was extracted by Integrated information system (IRIS), where the toxicity reference dose (RfD) is $0.0003 \mathrm{mg} / \mathrm{kg} /$ day and cancer slope factor (CSF) for arsenic is $1.5 \mathrm{mg} / \mathrm{kg} /$ day $(11,12)$.

\subsubsection{Exposure Assessment}

The concentrations of arsenic in water are determined from rural water supply distribution. In addition, the intensity, duration, and frequency of exposure to arsenic in drinking water were assessed by the questionnaire and interview with settlements of rural regions. The interview was conducted to collect all exposure factors. A bout questionnaire questions that used to estimate of intake contain body weight, the duration of frequency, and the exposure duration. The reliability of the questionnaire by alpha coefficient 0.87 was determined. With consideration, arsenic enters into the human body through several pathways; the average daily dose (ADD) through drinking water intake was calculated.

Average daily dose (ADD) for deterministic risk assessment and lifetime average daily dose (LADD) for cancer effects were calculated according to the following equations $(13,14)$ :

$$
\begin{aligned}
& A A D=\frac{C \times I R \times E D \times E F}{B W \times A T} \\
& L A A D=\frac{C \times I R \times E D \times E F}{B W \times A T}
\end{aligned}
$$

At above equation C: represent the amount of Arsenic in rural drinking water $(\mu \mathrm{g} / \mathrm{L})$

IR: water consumption for individuals less than 13 years old 1 lit/day and anyone older than this age 2 lit/day was considered.

ED: exposure duration with regard to the age range of population containing $0-14$ and 15 - 65, respectively.

EF: exposure duration (365 day/year)

BW: body weight for people under 15 years old. The weight of $50 \%$ of the corresponding WHO age-weight curve was considered for 15 years old and older as $70 \mathrm{~kg}$.

AT: average life time $($ ED $\times 365$ days/years $)$

ADD and LADD were expressed in $\mathrm{mg} / \mathrm{kg} / \mathrm{y}$ 


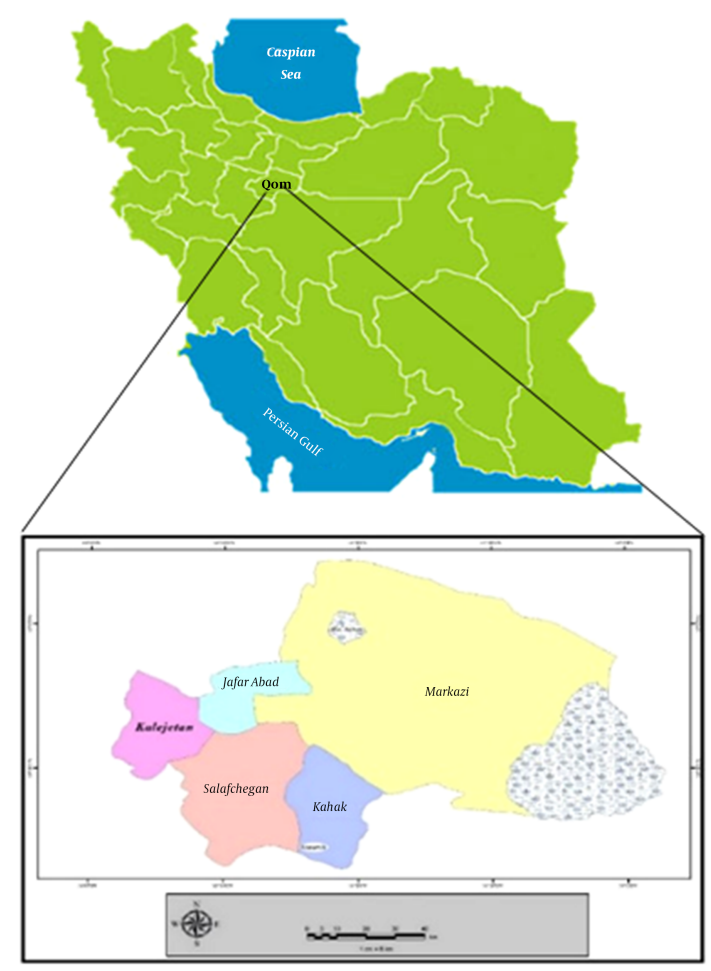

Figure 1. Location of Studied Area and Sampling Points

\subsection{Risk Characterization}

Risk characterization was carried for deterministic risk assessment by hazard quotient (HQ) and cancer effects. Hazard quotient (HQ) was estimated through Equation 3:

$H Q=\frac{A D D}{R f D}$

Cancer risk (CR) was calculated by the following equation:

$C R=\mathrm{LADD} \times C S F$

For cancer risk results, the acceptable level of 1 case per 10,000 is set in this study.

\section{Results}

\subsection{Arsenic Concentration in Rural Water Supply System}

Results of study showed that the concentrations of arsenic in rural water supply system are 0 to $30 \mu \mathrm{g} / \mathrm{L}$ (mean value of $3.16 \mu \mathrm{g} / \mathrm{L}$ and $\sigma= \pm 4.86$ ) as shown in Table 1. More than $16 \%$ of the rural population was exposed to arsenic with level above $10 \mu \mathrm{g} / \mathrm{L}$ and $70 \%$ of the population was exposed to arsenic with levels 1 to $10 \mu \mathrm{g} / \mathrm{L}$.
Rural regions of Kahak County did not meet the standard for concentration (mean value of $10.12 \mu \mathrm{g} / \mathrm{L}$ and $\sigma=$ \pm 6.29 ). The rate of hardness and alkalinity in the Kahak County (mean value of $371 \mathrm{mg} / \mathrm{L}, \sigma= \pm 143$ and $231 \mathrm{mg} / \mathrm{L}, \sigma$ $= \pm 74.1$ ) was determined, respectively. The results of water sampling from 5 counties of Qom province consisted of Kahak, Salafchegan, Markazi, Dastjerd, and Jafarieh about physico-chemical parameters ( $\mathrm{pH}$, As, Alkalinity and Hardness) are also represented in Table 1.

\subsection{Health Risk Assessment}

Considering the results of arsenic concentration in drinking water of the rural population, it is obvious that the major exposure with arsenic in drinking water is related to the region of Kahak County (mean value of $>10$ $\mu \mathrm{g} / \mathrm{L})$, which is much higher than the Iranian National drinking water standard and WHO guidance (1). Therefore, the exposure risk assessment was applied for the region of Kahak County. A survey on the demographic categories for amounts of water consumption from the distribution water supply system in Kahak County region was done by applying the exposure parameter and was evaluated from an interview and a structure questionnaire including detailed questions on the variable used to estimate the intake 
Table 1. $\mathrm{pH}$, Alkalinity, Hardness an As in Collected Samples

\begin{tabular}{|c|c|c|c|c|c|}
\hline County & Rural Region & $\mathrm{pH}$ & As, ppb & Hardness & Alkalinity \\
\hline \multirow{5}{*}{ Markazi } & Qomrud & 7.95 & 2 & 313 & 150 \\
\hline & Ganavat & 6.31 & 2 & 98 & 50 \\
\hline & Agholak & 6.9 & 0 & 310 & 100 \\
\hline & Kalageneshin & 7.1 & 0 & 350 & 260 \\
\hline & Eslamabad & 8.09 & 0 & 250 & 150 \\
\hline \multirow{22}{*}{ Kahak } & Kahak & 8 & 8 & 290 & 210 \\
\hline & Bidhand & 7.21 & 4 & 360 & 213 \\
\hline & Fordo & 7.80 & 6 & 245 & 180 \\
\hline & Kermejagan & 7.64 & 8 & 200 & 190 \\
\hline & Veshnaveh & 7.42 & 12 & 294 & 250 \\
\hline & Venarch & 7.80 & 30 & 800 & 450 \\
\hline & Khaveh & 7.50 & 12 & 450 & 290 \\
\hline & Khurabad & 7.90 & 3 & 380 & 200 \\
\hline & Khadijehkhatun & 7.10 & 15 & 500 & 280 \\
\hline & Abarjes & 7.70 & 10 & 500 & 250 \\
\hline & Siru & 6.8 & 11 & 370 & 220 \\
\hline & Virij & 8.09 & 5 & 180 & 140 \\
\hline & Dastgerd & 7.10 & 7 & 378 & 167 \\
\hline & Verjan & 7.20 & 7 & 310 & 145 \\
\hline & Meiam & 7.40 & 12 & 360 & 190 \\
\hline & Zanburak & 7.50 & 12 & 400 & 280 \\
\hline & Salafchegan & 7.63 & 2 & 650 & 310 \\
\hline & Rahjerd & 7.70 & 2 & 607 & 308 \\
\hline & Tajkhatun & 8.08 & 1 & 100 & 250 \\
\hline & Jandab & 8.30 & 2 & 100 & 200 \\
\hline & Disijan & 7.90 & 1 & 420 & 210 \\
\hline & Senjekan & 7.70 & 2 & 180 & 145 \\
\hline \multirow{6}{*}{ Salafchegan } & Ghalecham & 7.83 & 2 & 470 & 210 \\
\hline & Bagheiek & 7.71 & 2 & 450 & 220 \\
\hline & Enaiatbeik & 7.37 & 1 & 680 & 240 \\
\hline & Khalajabad & 7.60 & 2 & 480 & 250 \\
\hline & lekebagh & 7.30 & 0 & 460 & 270 \\
\hline & Jafarieh & 7.9 & 2 & 196 & 180 \\
\hline \multirow{6}{*}{ Jafarieh } & Pachian & 7.58 & 2 & 220 & 160 \\
\hline & Tagharud & 7.6 & 2 & 313 & 140 \\
\hline & Dastjerd & 7.70 & 0 & 170 & 210 \\
\hline & Ghahan & 7.55 & 0 & 411 & 210 \\
\hline & Zizegan & 7.56 & 1 & 100 & 200 \\
\hline & Sanavand & 7.61 & 0 & 300 & 240 \\
\hline \multirow{5}{*}{ Dastjerd } & Eslamabad & 7.40 & 1 & 350 & 185 \\
\hline & Ahmadabad & 7.66 & 1 & 390 & 240 \\
\hline & Varzaneh & 7.20 & 1 & 210 & 105 \\
\hline & Hasanabad & 7.52 & 1 & 690 & 230 \\
\hline & Veshareh & 7.63 & 1 & 210 & 220 \\
\hline
\end{tabular}

amounts such as: body weight, duration, frequency, and exposure duration. With consideration to most cases, arsenic concentration for all of rural area of Kahak county were not available and therefore we assumed the As concentration value of $30 \mu \mathrm{g} / \mathrm{L}$, which corresponds to a worstcase scenario (equally of As concentration of venarch re- gion in the Kahak county).

The results determined that 2 group for exposure dose must be considered. Group 1: exposed population containing individuals from 0 - 14 years old with the annual water intake of $0.5 \mathrm{~L} / \mathrm{d}$. Group 2 : the exposed population with the average age ranged from 15 - 65 years old with the annual 
intake of $1 \mathrm{~L} / \mathrm{d}$. The exposure dose for arsenic in drinking water was calculated for the 2 mentioned groups are represented in Tables 2 and 3.

For risk characterization at this study, the deterministic risk assessment (non-cancer effects) and the stochastic risk assessment were estimated. In this method, the protocols and criteria related to USEPA (12) were considered. The results of risk characterization for the 2 groups in this study are represented in Table 4.

\section{Discussion}

The results of this study, especially with considering the outputs of risk characterization (Table 3) for noncarcinogenic effects by arsenic in drinking water of Venarch region of Kahak county indicated that the hazard quotient (HQ) for Group 1 and Group 2 is higher than 1 (HQ $>1$ ) and the possibility of risk of disease for 2 groups especially individuals within the age of 15 - 65 years old. Of course, these concentrations of arsenic can cause the adverse health effects on children with the ages lower than 14 years.

In the cancer risk assessment, the cumulative probability of total risk calculated by using the Monte Carlo simulation is shown in Figures 2 and 3. The mean cancer risk calculated for group 1 was $76 \times 10^{-5}$ based on point estimation, however, as shown in Figure 2, the $90 \%$ probability CR for group 1 exposed to As concentration with $>10 \mu \mathrm{g} / \mathrm{L}$, ranged from $63.5 \times 10^{-5}$ to $88.5 \times 10^{-5}$. The mean cancer risk calculated for Group 2 was $42 \times 10^{-5}$ based on point estimation. In Figure 3, the 90\% probability CR for Group 2 exposed to As concentration with $>10 \mu \mathrm{g} / \mathrm{L}$ ranged from $35 \times 10^{-4}$ to $48 \times 10^{-4}$.

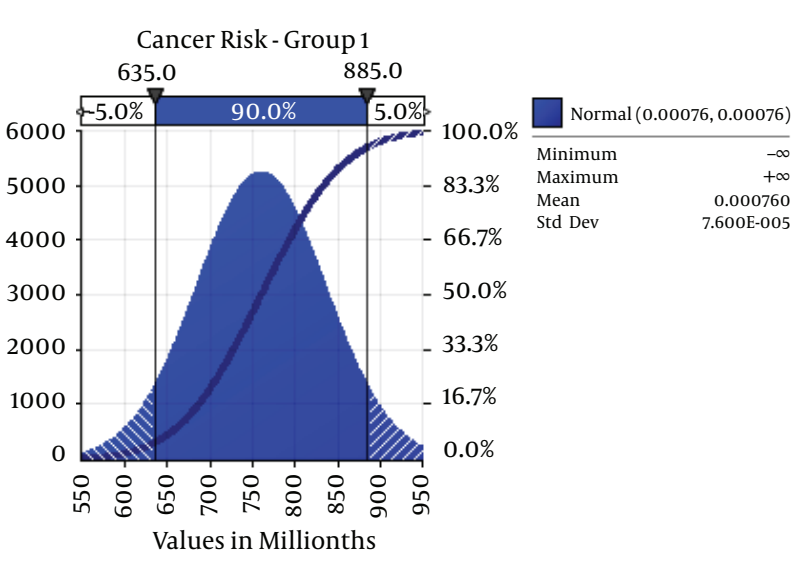

Figure 2. Cancer Risk Assessment for Group 1

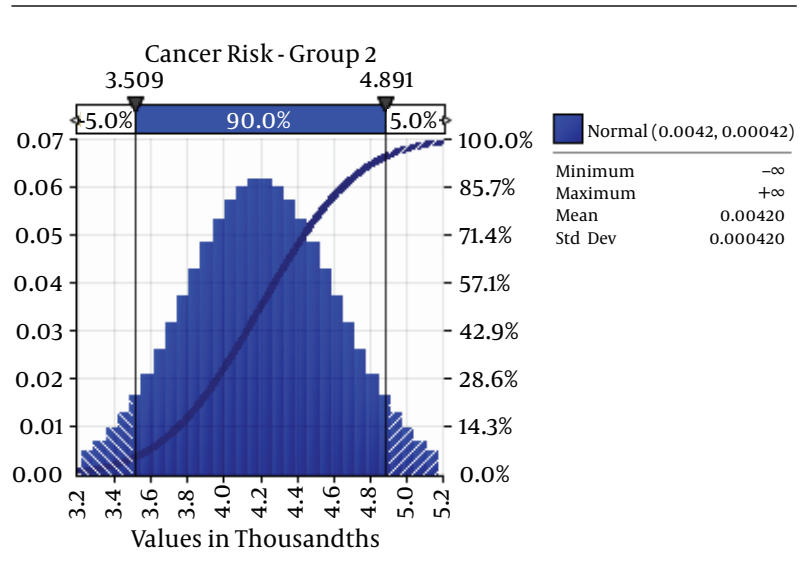

Figure 3. Cancer Risk Assessment for Group 2

For carcinogenic effects, considering $10^{-4}$ as a limit for $\mathrm{CR}(7,12,13)$, the results are indicated that the individual in the rural regions of Kahak county are exposed to arsenic in drinking water. The concentration of $30 \mu \mathrm{g} / \mathrm{L}$ of arsenic are known to have a very high risk for cancer due to the fact that the cancer risk for the 2 group are more than 7.6 and 42 times the EPA criteria, respectively. With regard to the results of this study, although the low Arsenic exposure by drinking water and with intake rate of $(0.5 \mathrm{~L} /$ day $)$ and the concentration of arsenic in drinking water was 3 times higher compared to the recommended international standards $(10 \mu \mathrm{g} / \mathrm{L})(1)$, the potential risk for non-carcinogenic effects and carcinogenic effects have been increased.

This result was comparable to the other studies that ar carried out in other countries. In the study of arsenic in drinking water toxicological risk assessment in the North Region of Burkina Faso, arsenic concentration ranged from 0 up to 87.8 micrograms per liter. The risk induced by arsenic for non- cancer effects when children are aged between 0 - 14 are subject to arsenic concentrations below $87 \mathrm{~g} / \mathrm{L}$. The risk is huge in all cases and HQ > 1 for carcinogenic effects (13). In another study of a population chronically exposed to arsenic through drinking water from Argentina, a wide range of concentration from non-detectable (ND) to $2000 \mu \mathrm{g} / \mathrm{L}$, in $68 \%$ of the locations of the study, the population had a HQ greater than 1, and the $\mathrm{CR}$ ranged between $5 \times 10^{-5}$ and $2.1 \times 10^{-2}(9)$. Health risk assessment for exposure to arsenic in drinking water in Hanam Province, Vietnam, showed that arsenic concentrations in tube-well water ranged from 8-579 ppb and the skin cancer risk would be 11.5 times higher if the water was not filtered with water induced potential risk for population (15). The results of the study regarding exposure of children to arsenic in drinking water in the Tharparkar region of Sindh, Pakistan, indicated that 2 age groups (5 - 10 
Table 2. Exposure Dose for Deterministic Effects (Non-Cancer Effects)

\begin{tabular}{|c|c|c|c|c|c|c|c|}
\hline & Group & $\mathbf{C}, \mu \mathrm{g} / \mathbf{L}$ & IR, $\mathbf{L} / \mathbf{d}$ & BW, kg & ED, $y$ & $E F, d / y$ & ADD, $\mathrm{mg} / \mathrm{kg} / \mathrm{y}$ \\
\hline \multirow{2}{*}{ Non-Cancer Effects } & 1 & 30 & 0.5 & 29 & 7 & 365 & $5 \times 10^{-4}$ \\
\hline & 2 & 30 & 1 & 50 & 33 & 365 & $6 \times 10^{-4}$ \\
\hline
\end{tabular}

Table 3. Exposure Dose for Stochastic Effects (Cancer Effects)

\begin{tabular}{|c|c|c|c|c|c|c|c|c|}
\hline & Group & $\mathbf{C}, \mu \mathbf{g} / \mathbf{L}$ & IR, $\mathbf{L} / \mathbf{d}$ & BW, kg & ED, y & $E F, d / y$ & AT & LADD, mg/kg/y \\
\hline \multirow{2}{*}{ Cancer Effects } & 1 & 30 & 0.5 & 29 & 7 & 365 & 25550 & $5.1 \times 10^{-5}$ \\
\hline & 2 & 30 & 1 & 50 & 33 & 365 & 25550 & $28 \times 10^{-4}$ \\
\hline
\end{tabular}

Table 4. Outputs of Risk Characterization

\begin{tabular}{lcccc}
\hline Group & Non-Cancer Effects & & Cancer Effects \\
\cline { 2 - 5 } & ADD & HQ & LADD & CR \\
\hline $\mathbf{2}$ & $5.1 \times 10^{-4}$ & 1.7 & $5.1 \times 10^{-5}$ & $28 \times 10^{-5}$ \\
\hline
\end{tabular}

and 11 - 14 years) exposed to total arsenic concentration in the groundwater was $6.51-9.98 \mu \mathrm{g} / \mathrm{L}$ and in addition, HQ (2.2 - 2.3) was determined (14). Figures 4 and 5 represented the correlation observed between the amount of arsenic concentration versus hardness and alkalinity measured in the rural drinking water of Qom province.

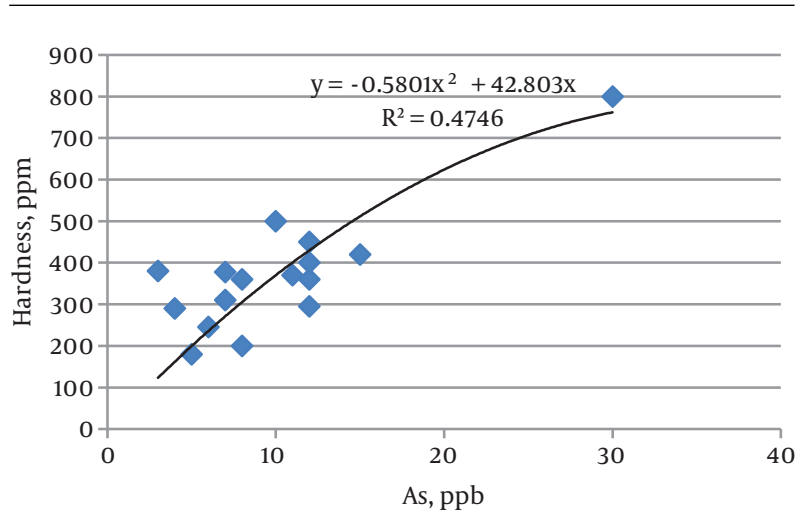

Figure 4. Arsenic Concentration Versus Hardness of Drinking Water in the Kahak County

The results in Figure $5\left(\mathrm{R}^{2}=0.47\right.$, P value $\left.<0.05\right)$ and Figure $4\left(R^{2}=0.51\right.$, P value $\left.<0.05\right)$ exhibited a small correlation between high levels of arsenic concentration in drinking water of rural regions of Kahak County with a rate of hardness and alkalinity. In the study of Benner et al. statistical analyses reveal that a positive exists between total hardness of groundwater and the arsenic content in it. It

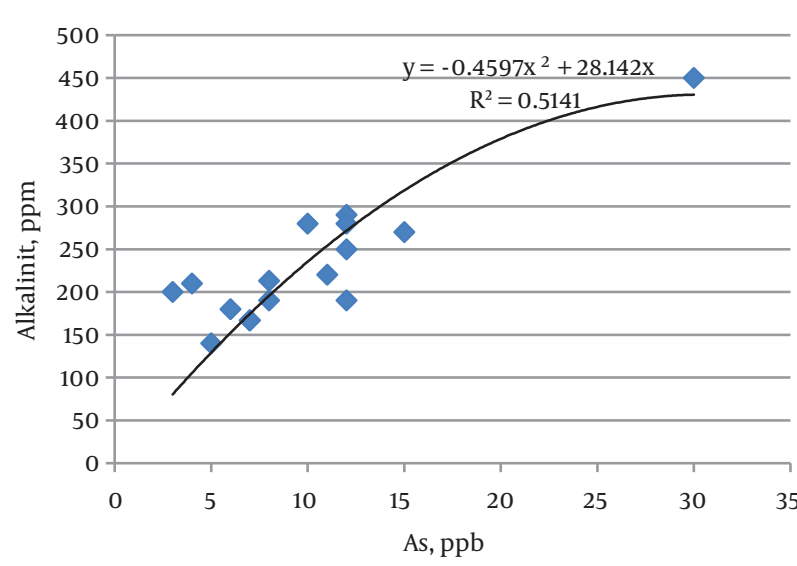

Figure 5. Arsenic Concentration Versus Alkalinity of Drinking Water in the Kahak County

is determined that mining activities has an important role in increasing of arsenic concentration (16-18).

\section{Conclusions}

In this study, the exposure of drinking water was assessed. However, not only water but also the food sources are the major potential source of arsenic exposure in the polluted areas. It is obvious that the mining activities such as magnetic extraction in the rural region of Kahak County induced the increasing of arsenic in drinking water sources. 
The lack of local awareness and poor reporting of the health aspects of arsenic in drinking water in Kahak region are the main obstacles for control of adverse effects of arsenic problems. Therefore, it is recommended that for the first time, the source and water supply system in rural region of Kahak is substituted with safe drinking water as well as providing health facilities and screening tests for exposed populations.

\section{Acknowledgments}

The authors would like to thank the Qom University of Medical Sciences for their financial support of this study. We would also like to thank the technical staff in the laboratory.

\section{Footnote}

Authors' Contribution: Conceived and designed the experiments: Amir Hossein Mahvi, Edris Bazrafshan; performed the experiments: Zahra Atafar, Mohammad Khazaie; analyzed the data: Hossein Kamani; wrote the manuscript: Yadollah Ghafuri.

\section{References}

1. George CM, Sima L, Arias MH, Mihalic J, Cabrera LZ, Danz D, et al. Arsenic exposure in drinking water: an unrecognized health threat in Peru. Bull World Health Organ. 2014;92(8):565-72. doi: 10.2471/BLT.13.128496. [PubMed: 25177071].

2. Mosaferi M, Yunesian M, Dastgiri S, Mesdaghinia A, Esmailnasab N. Prevalence of skin lesions and exposure to arsenic in drinking water in Iran. Sci Total Environ. 2008;390(1):69-76. doi: 10.1016/j.scitotenv.2007.09.035. [PubMed: 17997470].

3. Du M, Wei D, Tan Z, Lin A, Du Y. The potential risk assessment for different arsenic species in the aquatic environment. J Environ Sci (China). 2015;27:1-8. doi: 10.1016/j.jes.2014.03.006. [PubMed: 25597657].

4. Nordstrom DK. Public health. Worldwide occurrences of arsenic in ground water. Science. 2002;296(5576):2143-5. doi: 10.1126/science.1072375. [PubMed: 12077387].

5. Tsuji JS, Perez V, Garry MR, Alexander DD. Association of low-level arsenic exposure in drinking water with cardiovascular disease: a systematic review and risk assessment. Toxicology. 2014;323:78-94. doi: 10.1016/j.tox.2014.06.008. [PubMed: 24953689].
6. Sohel N, Persson LA, Rahman M, Streatfield PK, Yunus M, Ekstrom EC, et al. Arsenic in drinking water and adult mortality: a population-based cohort study in rural Bangladesh. Epidemiology.2009;20(6):824-30. doi:10.1097/EDE.0b013e3181bb56ec. [PubMed: 19797964].

7. Phan K, Sthiannopkao S, Heng S, Phan S, Huoy L, Wong MH, et al. Arsenic contamination in the food chain and its risk assessment of populations residing in the Mekong River basin of Cambodia. J Hazard Mater. 2013;262:1064-71. doi: 10.1016/j.jhazmat.2012.07.005. [PubMed: 22818591].

8. Kumar M, Puri A. A review of permissible limits of drinking water. Indian J Occup Environ Med. 2012;16(1):40-4. doi: 10.4103/00195278.99696. [PubMed: 23112507]

9. Navoni JA, De Pietri D, Olmos V, Gimenez C, Bovi Mitre G, de Titto E, et al. Human health risk assessment with spatial analysis: study of a population chronically exposed to arsenic through drinking water from Argentina. Sci Total Environ. 2014;499:166-74. doi: 10.1016/j.scitotenv.2014.08.058. [PubMed: 25181048].

10. Huy TB, Tuyet-Hanh TT, Johnston R, Nguyen-Viet H. Assessing health risk due to exposure to arsenic in drinking water in Hanam Province, Vietnam. International journal of environmental research and public health. 2014;11(8):7575-91.

11. Uddh-Soderberg TE, Gunnarsson SJ, Hogmalm KJ, Lindegard MI, Augustsson AL. An assessment of health risks associated with arsenic exposure via consumption of homegrown vegetables near contaminated glassworks sites. Sci Total Environ. 2015;536:189-97. doi: 10.1016/j.scitotenv.2015.07.018. [PubMed: 26204055].

12. Abernathy CO, Thomas DJ, Calderon RL. Health effects and risk assessment of arsenic. J Nutr. 2003;133(5 Suppl 1):1536S-8S. [PubMed: 12730460].

13. Nzihou JF, Bouda M, Hamidou S, Diarra J. Arsenic in Drinking Water Toxicological Risk Assessment in the North Region of Burkina Faso. Journal of Water Resource and Protection. 2013;5(8):46-52. doi: 10.4236/jwarp.2013.58A007.

14. Brahman KD, Kazi TG, Afridi HI, Baig JA, Arain SS, Talpur FN, et al. Exposure of children to arsenic in drinking water in the Tharparkar region of Sindh, Pakistan. Sci Total Environ. 2016;544:653-60. doi: 10.1016/j.scitotenv.2015.11.152. [PubMed: 26674695].

15. Huy TB, Tuyet-Hanh TT, Johnston R, Nguyen-Viet H. Assessing health risk due to exposure to arsenic in drinking water in Hanam Province, Vietnam. Int J Environ Res Public Health. 2014;11(8):7575-91. doi: 10.3390/ijerph110807575. [PubMed: 25062276].

16. Benner SG, Polizzotto ML, Kocar BD, Ganguly S, Phan K, Ouch $\mathrm{K}$, et al. Groundwater flow in an arsenic-contaminated aquifer, Mekong Delta, Cambodia. Applied Geochemistry. 2008;23(11):3072-87. doi: 10.1016/j.apgeochem.2008.06.013.

17. Saipan P, Ruangwises S. Health risk assessment of inorganic arsenic intake of Ronphibun residents via duplicate diet study. J Med Assoc Thai. 2009;92(6):849-55. [PubMed:19530592].

18. Polizzotto ML, Kocar BD, Benner SG, Sampson M, Fendorf S. Near-surface wetland sediments as a source of arsenic release to ground water in Asia. Nature. 2008;454(7203):505-8. doi: 10.1038/nature07093. [PubMed:18650922]. 